\title{
SPECTROSCOPIC TECHNIQUES COMBINED WITH CHEMOMETRICS TO STUDY ORGANIC MATTER IN TROPICAL SOILS WITH DIFFERENT DEGREES OF PEDOGENETIC EVOLUTION
}

\author{
Octávio Vioratti Telles de Moura ${ }^{a}$, Tadeu Augusto van Tol de Castroa, Danielle de Oliveira França ${ }^{a}$, Orlando Carlos Huertas

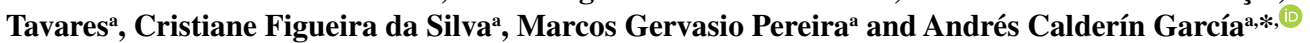 \\ aDepartamento de Solos, Universidade Federal Rural do Rio de Janeiro, 23890-000 Seropédica - RJ, Brasil
}

Recebido em 25/04/2021; aceito em 12/07/2021; publicado na web em 03/08/2021

\begin{abstract}
Understanding of the organomineral interactions in soil can elucidate the humic substances (HS) formation and the humification process. This study aimed to structurally characterize the humic acids (HA) formed in tropical soils with different pedogenesis degrees. The HA fraction was extracted from soil samples in the superficial horizons of an Inceptisol and a Mollisol in Rio de Janeiro state. The HA was characterized using spectroscopic techniques following by chemometric analyses: principal component analysis, descriptive analysis, and multivariate curve resolution. The results show that HA extracted from superficial horizon of Inceptisol and Mollisol are structurally different. The Inceptisol HA has a lower $\mathrm{E}_{4} / \mathrm{E}_{6}$ ratio than the Mollisol HA. The chemical groups show that most $-\mathrm{CH}$ groups belong to $-\mathrm{CH}_{2}$ and $-\mathrm{CH}_{3}$ and hydroxyls $(-\mathrm{OH})$ for the Inceptisol HA, whereas the Mollisol HA predominantly contains aromatic $\mathrm{C}=\mathrm{C}$ groups. The Inceptisol $\mathrm{HA}$ is mainly composed of $\mathrm{C}_{\mathrm{Alkyl}} \mathrm{H}, \mathrm{R}$ and $-\mathrm{C}=\mathrm{O}$ structures, whereas the Mollisol $\mathrm{HA}$ contains a higher quantity of $\mathrm{C}_{\mathrm{Alkyl}} \mathrm{O}, \mathrm{N}, \mathrm{C}_{\mathrm{Alkyl}} \mathrm{O}$ and $\mathrm{C}_{\mathrm{Aromati}}-\mathrm{H}, \mathrm{R}$ groups. The Inceptisol $\mathrm{HA}$ has a higher aliphatic content and hydrophobicity than the Mollisol HA. In Inceptisol, organic carbon stabilization can be facilitated by hydrophobic interactions, whereas in Mollisol, different interaction sites can stabilize proteinaceous compounds.
\end{abstract}

Keywords: Mollisol; Inceptisol; humic substances; spectroscopy.

\section{INTRODUCTION}

The mechanisms for stabilizing organic carbon in soil depend on the chemical interactions between soil organic matter (SOM) and the mineral fraction. Organic compounds in soil originate from animal and plant residues and therefore have different structures, some of which can be highly complex, as in biomolecules and biopolymers. ${ }^{1-5}$ This complexity of the organic molecular structure, together with the chemical, physical and biological conditions of soil, regulate the interaction mechanisms and therefore the extent of mineralization and/or humification processes that generate carbon stock..$^{6-12}$

The chemical mechanisms for the humification of SOM are perhaps one of the most studied topics in soil science today. Previously, permanent organic carbon in soil was considered to derive from physical preservation or interactions between simpler molecules and was not associated with the formation of humified supra-structures. ${ }^{13,14}$ Schmidt et al. ${ }^{13}$ and Kleber and Lehmann. ${ }^{15}$ reported that the persistence of organic matter (OM) in soil does not occur due to the intrinsic properties in themselves, but because of the biological and biochemical environmental characteristics that reduce its decomposition rate, that is, the persistence of OM in the soil does not respond to a molecular property, but an ecosystem property. In this same line Lehmann and Kleber ${ }^{14}$ report that the persistence of SOM is governed following the continuum model based on the interactions of organic compounds with the mineral matrix of the soil. Current understanding of the humification process involves the formation of humic substances (HS) via weak inter-molecular bonds $(\pi-\pi, \pi-\mathrm{CH}$ and van der Waals) that are thermodynamically repelled from the soil solution to form a humic superstructure. , $^{6,16,17}$

Spectroscopic techniques are generally used to study SOM characterization. ${ }^{6,9,18,19}$ Structural characterization shows small hydrophilic molecules interact via hydrogen bonding, whereas larger aromatic and nonpolar molecules associate via hydrophobic

*e-mail: cg.andres@gmail.com interactions. ${ }^{20}$ Others studies revealed that highly condensed or strongly associated rigid aromatic systems interact with carboxyl groups, involved in hydrogen-bondings formation, and mobile $\mathrm{C}-\mathrm{O} / \mathrm{C}-\mathrm{N}$ systems that, in turn, should be mainly displaced, as well as the mobile alkyl moieties, on the surface of the solid-state humic acids (HA). ${ }^{21}$ Studies on the soil surface layer show that the stability of the bonds between organic compounds and clay decrease in the following order: lignin (dimers)/alkyl aromatics $>$ phenols/lignin (monomers) $>$ carbohydrates/nitrogen compounds. ${ }^{22}$

Under tropical climatic conditions, humified organic carbon stock is the most important soil component for the preservation of soil fertility and structure. ${ }^{23,24}$ Soils with different pedogenetic degrees can constitute a natural model to study the formation of humic fractions in soil. Inceptisol and Mollisol have different degrees of pedogenetic evolution. Inceptisols have a low pedogenetic degree evolution, for which a specific pedogenetic process cannot be identified, whereas Mollisols have the naturally high fertility of a mollic horizon. Such soils can exhibit different classes of textures, which affect the transformation dynamics and stabilization of soil organic carbon. ${ }^{25}$

Recent studies have shown that humification is a physical, chemical, and biochemical process, whereby some of the organic carbon in soil is stabilized through the formation of a humic superstructure. ${ }^{6,7,16,17}$ The thus-formed HS have similar structures, irrespective of origin, but may be composed of different functional groups depending on the molecules that initiate the humification and the kinetic and thermodynamic path of the corresponding reactions. ${ }^{7}$

Although advances in understanding humification have been made in recent years, little is known about organomineral interactions in soils with a low degree of pedogenetic evolution and the effect of texture on carbon humification under tropical climatic conditions. This study is the first report on the molecules that participate in HA formation in soils with different textural classes and different degree of pedogenetic evolution. The objective of this study is to combine spectroscopic structural characterization with chemometric 
techniques to characterize humified SOM in an Inceptisol and a Mollisol.

\section{EXPERIMENTAL}

Samples were collected from the superficial horizons of two soil classes: Inceptisol ${ }^{26}$ from Cambisolo Háplico, ${ }^{27}$ which is a typical aluminum-containing soil, and Mollisol $^{26}$ from Chernossolo Háplico Ortico léptico ${ }^{27}$ in the Pinheiral (RJ) municipality. The primary vegetation in these areas is of the seasonal semideciduous forest type. The current use of the Inceptisol area is pasture with grass colonization (Panicum maximum Jacq.). The Mollisol area is used for pasture vegetation with brachiaria (Urochloa decumbes Stapf.). The lithology of the Mollisol area is mafic dyke (gabbro) and that of Inceptisol is colluvial sediments (Figure 1). For each area, 10 composite samples were collected, each consisting of five simple samples. The samples were collected at a unique depth of $0-20 \mathrm{~cm}$. Locations with minimal anthropogenic interference were chosen. After collection, the material was dried and passed through a 2-mm sieve to obtain thin soil air-dried (TSAD) for laboratory analysis. Inceptisol has a sandy loam texture (sand: $480.1 \mathrm{~g} \mathrm{~kg}^{-1}$, coarse sand: $315.8 \mathrm{~g} \mathrm{~kg}^{-1}$, fine sand: $164.3 \mathrm{~g} \mathrm{~kg}^{-1}$ silt: $229.2 \mathrm{~g} \mathrm{~kg}^{-1}$ and clay: $255.9 \mathrm{~g} \mathrm{~kg}^{-1}$ ), whereas Mollisol has a clay loam texture (sand: $239.8 \mathrm{~g} \mathrm{~kg}^{-1}$, coarse sand: $109.1 \mathrm{~g} \mathrm{~kg}^{-1}$, fine sand: $130.7 \mathrm{~g} \mathrm{~kg}^{-1}$, silt: $341.9 \mathrm{~g} \mathrm{~kg}^{-1}$ and clay: $372.0 \mathrm{~g} \mathrm{~kg}^{-1}$ ).

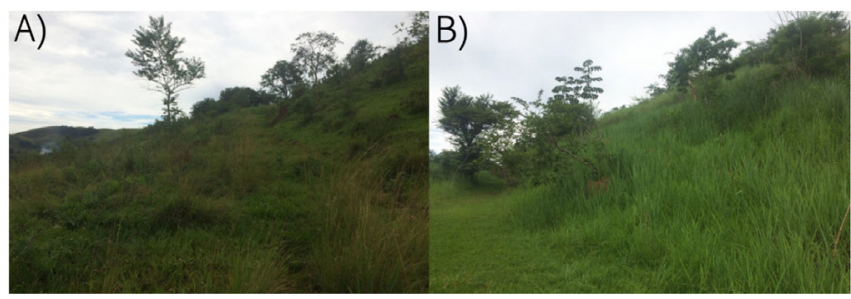

Figure 1. Area location of Mollisol (A) and Inceptisol (B), Pinheiral (RJ)

\section{Chemical and physical analyses of soil samples}

The $\mathrm{Ca}^{2+}, \mathrm{Mg}^{2+}$ and $\mathrm{Al}^{3+}$ contents of the soils were determined using a $\mathrm{KCl} 1 \mathrm{~mol} \mathrm{~L}^{-1}$ solution, and the $\mathrm{H}^{+}+\mathrm{Al}^{3+}$ content in the soils was determined using a $\mathrm{C}_{4} \mathrm{H}_{6} \mathrm{CaO}_{4}\left(0.5 \mathrm{~mol} \mathrm{~L}^{-1}\right)$ solution at $\mathrm{pH}$ 7.0. The $\mathrm{P}, \mathrm{Na}^{+}$and $\mathrm{K}^{+}$elemental contents were determined using a double acid solution $\left(\mathrm{H}_{2} \mathrm{SO}_{4} 0.0125 \mathrm{~mol} \mathrm{~L}^{-1}\right.$ and HCL $\left.0.05 \mathrm{~mol} \mathrm{~L}^{-1}\right)$. $^{28}$ The total organic carbon (TOC) was determined following the methodology of Yeomans and Bremner, ${ }^{29}$ and the humic fractions (C-AF, C-AH and C-Hum) were quantified following Benites et al.. ${ }^{30}$ The ash content for HA, fulvic acids (FA) and humins was $0.98 \%$, $0.95 \%$ and $1.01 \%$ respectively, obtained by gravimetry methods according to Song et l. $^{31}$

\section{Isolation and purification of HA extracted from superficial Inceptisol and Mollisol}

The HA were isolated and purified following the methodology recommended by the International Humic Substances Society (IHSS) and the protocol described by Swift. ${ }^{32}$ Briefly, HA was extracted from both soils by initial pretreatment with $\mathrm{HCl}\left(10^{-3} \mathrm{~mol} \mathrm{~L}^{-1}\right)$ to eliminate soluble salts. Subsequently, the soils were washed with $\mathrm{KOH}$ $\left(0.01 \mathrm{~mol} \mathrm{~L}^{-1}\right)$ to decrease the $\mathrm{pH}$ to neutral. The humus extraction was carried out by adding a $\mathrm{NaOH}\left(0.1 \mathrm{~mol} \mathrm{~L}^{-1}\right)$ solution to the soils in 10:1 (m:v) proportions under a $\mathrm{N}_{2}$ atmosphere, followed by mechanical agitation of the mixture for $24 \mathrm{~h}$. The supernatant (liquid humus) was then siphoned off, leaving the solid fraction. The humus was centrifuged at $10.000 \mathrm{~g}$ for 30 minutes, and the supernatant containing the dissolved humic substances (HA) was collected.

The dissolved humic fractions were separated by precipitating the HA fraction. For this purpose, the $\mathrm{pH}$ (approximately 10) of the obtained humus was adjusted to $\mathrm{pH}=2.0$ by dripping a $\mathrm{HCl}$ solution $\left(6.0 \mathrm{~mol} \mathrm{~L}^{-1}\right)$ and then left overnight for 16 hours, then, the HA (that is, the humic fraction that is insoluble at a $\mathrm{pH}$ below 2.0) was precipitated.

The mixture was then centrifuged at 5,000 $\mathrm{g}$ for $10 \mathrm{~min}$, and the supernatant was siphoned off: this process was repeated three times. The HA mixture was purified by adding $\mathrm{HF}\left(0.3 \mathrm{~mol} \mathrm{~L}^{-1}\right)+\mathrm{HCl}$ $\left(0.1 \mathrm{~mol} \mathrm{~L}^{-1}\right)$, followed by stirring for 24 hours. This process was repeated until HA ash content below $1 \%$ was obtained. Subsequently, the supernatant from each process was discarded, and the HA mixture was washed. The HA were re-dissolved in $\mathrm{KOH}\left(0.1 \mathrm{~mol} \mathrm{~L}^{-1}\right)$, and a $\mathrm{KCl}\left(0.3 \mathrm{~mol} \mathrm{~L}^{-1}\right.$ of $\left.\mathrm{K}^{+}\right)$solution was added to the mixture. The mixture was centrifuged at 4,000 $\mathrm{g}$ for $15 \mathrm{~min}$, and the precipitated solid was discarded. The HA were reconstituted by adding $\mathrm{HCl}$ $\left(6.0 \mathrm{~mol} \mathrm{~L}^{-1}\right)$ to decrease the $\mathrm{pH}$. The HA were then dialyzed against deionized water using SPECTRA/POR ${ }^{\circ} 7$ dialysis tubing, $1 \mathrm{kD}$, up to electrical conductivity values less than $1 \mu \mathrm{S}$ and negatively tested for $\mathrm{Cl}^{-}$ions using $\mathrm{AgNO}_{3}$. Lastly, the HA were frozen in a freezer at $-80{ }^{\circ} \mathrm{C}$ and later lyophilized.

\section{Structural characterization of HA extracted from superficial Inceptisol and Mollisol}

\section{Characterization of HA by ultraviolet-visible spectroscopy (UV-vis)}

A total of $5 \mathrm{mg}(\mathrm{C}) \mathrm{L}^{-1}$ of the HA fraction was dissolved in sodium hydrogen carbonate $\left(\mathrm{NaHCO}_{3}\right)$. Twenty spectra, ten for each HA extracted, were recorded for each soil type in the UV-vis region (200 $\mathrm{nm}-700 \mathrm{~nm}$ ) at a $10 \mathrm{~nm}$ resolution. The spectra were obtained using a Shimadzu UV-1800 UV/visible scanning spectrophotometer. The absorbances at $465 \mathrm{~nm}$ and $665 \mathrm{~nm}$ were used to calculate the $\mathrm{E}_{4} / \mathrm{E}_{6}{ }^{33}$

\section{Characterization of HA by attenuated total reflection Fourier} transform infrared spectroscopy (ATR - FTIR)

The spectra were obtained at the PPGQ/UFRRJ Multi-User Analytical Center. The spectra were recorded in the 4.00 to $4.000 \mathrm{~cm}^{-1}$ region at a $4 \mathrm{~cm}^{-1}$ resolution, and 32 scans were collected for each measurement. For this purpose, a VERTEX 70/70v FTIR spectrometer (Bruker Corporation, Germany) was coupled to a platinum diamond attenuated total reflection device (ATR), wherein a diamond disk functioned as an internal reflection element. The lyophilized HA were placed in the ATR crystal to record the spectra. An air spectrum was recorded and used as a blank before each analysis. The spectra were collected at a room temperature of approximately $20^{\circ} \mathrm{C}$. The spectra were collected using OPUS-Bruker software. All the spectra were subjected to baseline correction. A smoothing algorithm (SavitskyGolay) was used to increase the signal-to-noise ratio. Bands were identified by plotting the peak positions with the PeakPicking tool.

Characterization of HA by carbon 13 cross-polarization magicangle-spinning nuclear magnetic resonance spectroscopy $\left({ }^{13} \mathrm{C} \mathrm{NMR} C \mathrm{CP} / \mathrm{MAS}\right)$

A ${ }^{13} \mathrm{C}$ NMR CP/MAS analysis was performed at the Analytical Center using a PPGQ/UFRRJ on a 400-MHz Bruker AVANCE II NMR instrument, equipped with a 4-mm narrow MAS probe and operating in a 13-C resonance sequence from 100 to $163 \mathrm{MHz}$. The HA samples were placed in a rotor (sample holder) of zirconium dioxide $\left(\mathrm{ZrO}_{2}\right)$ with Kel-F caps at a rotation frequency of $8 \pm 1 \mathrm{kHz}$. The spectra were selected by collecting 3000 data points for a fixed number of scans over a capture time of $34 \mathrm{~ms}$ with a recycling delay 
of $5 \mathrm{~s}$. The contact time for the ${ }^{1} \mathrm{H}$ ramp sequence was $2 \mathrm{~ms}$. Spectral collection and elaboration were performed using Bruker Topspin 2.1 software. The free induction decays (DLI) were transformed by applying a zero-filling of $4 \mathrm{k}$, followed by an exponential function adjustment (line extension) of $70 \mathrm{~Hz}$. The spectra were analyzed using ACD/Labs software 2020.1.1. The spectra were then divided into different regions according to the carbon type using the PeakPicking tool. The regions were integrated over the total area using the "integration manual" tool. The following regions were identified: non-functionalized alkyl carbons $\left(\mathrm{C}_{\mathrm{Alkyl}}-\mathrm{H}, \mathrm{R}\right): 0-45$ ppm; C-methoxy and N-alkyl-C $\left(\mathrm{C}_{\text {Alkyl }} \mathrm{O}, \mathrm{N}\right)$ : 45-60 ppm; O-alkyl C $\left(\mathrm{C}_{\text {Alkyl }} \mathrm{O}\right)$ : 60-90 ppm; di-O-alkyl C (anomeric carbon) $\left(\mathrm{C}_{\mathrm{Alkyl}}-d i-\mathrm{O}\right)$ : 90-110 ppm; aromatic carbon $\left(\mathrm{C}_{\text {Aromatic }}-\mathrm{H}, \mathrm{R}\right)$ : $110-140 \mathrm{ppm}$; $\mathrm{O}$, $\mathrm{N}$-aromatic C $\left(\mathrm{C}_{\text {Aromatic }}-\mathrm{N}, \mathrm{O}\right)$ : $140-160 \mathrm{ppm}$; carboxyl C $\left(\mathrm{C}_{\mathrm{COO}}-\mathrm{H}, \mathrm{R}\right)$ : $160-185 \mathrm{ppm}$ and carbonyl $\mathrm{C}\left(\mathrm{C}_{\mathrm{C}=\mathrm{O}}\right): 185-230 \mathrm{ppm}$. The aromaticity index was calculated as $\left(\mathrm{C}_{\text {Aromatic }}-\mathrm{H}, \mathrm{R}\right)+\left(\mathrm{C}_{\text {Aromatic }}-\mathrm{O}, \mathrm{N}\right) * 100 /$ total area, and the aliphaticity index was calculated as 100 -aromaticity $(\%)$. The hydrophobicity index (HB/HI) was calculated using the following formula: $(0-46 \mathrm{ppm})+(110-156 \mathrm{ppm}) /(46-110 \mathrm{ppm})+$ $(156-110 \mathrm{ppm})+(156-186 \mathrm{ppm}) \cdot{ }^{31,34,35}$

\section{Chemical analysis of spectra data}

Chemometric analysis was performed using The Unscrambler software (version 10.4) (Camo Software AS, Nedre Vollgate 8, Oslo, Norway). The UV-vis spectra of the HA were loaded from saved data into an Excel spreadsheet. The ATR-FTIR and ${ }^{13} \mathrm{C}$ NMR CP/MAS spectra were loaded as "import data" from the spectral files. The UV-vis spectra loading generated a $20 \times 86$ matrix of samples. The UV-vis matrix was presented as a line plot for visual inspection and then transformed by "normalization". The normalized matrix was plotted using the matrix color tool. The ATR-FTIR spectra loading generated a 20 x 1852 matrix of samples. The ATR-FTIR matrix was presented as a line plot for visual inspection and subsequently transformed through "normalization", "smoothing-Savitsky-Golay" and baseline correction (that is, an offset-linear baseline correction). The transformed matrix was plotted the using matrix color tool. The ${ }^{13} \mathrm{C}-\mathrm{NMR} \mathrm{CP} / \mathrm{MAS}$ spectra loading generated a 20 x 4096 matrix of samples. The ${ }^{13} \mathrm{C}-\mathrm{NMR}$ CP/MAS matrix was presented as a line plot for visual inspection and subsequently transformed by "normalization", "smoothing" and baseline correction (that is, an offset-linear baseline correction).

The average spectra were obtained using the descriptive statistics tool and plotted in line form after accessing the results matrix. The matrix corresponding to the average spectra for each type of soil was then added to the original matrix to perform a multivariate data analysis. The standardized matrix was used to perform a principal component analysis (PCA). A total of seven components and automatic identification of outliers was used in the PCA model. A nonlinear iterative partial least squares (NIPALS) algorithm and cross validation were used. The scores and loadings were graphed separately, where the loadings were plotted in line form to visualize the weights as a spectral pattern.

After establishing the PCA model, multivariate curve resolution (MCR) was performed to decompose the complex matrix of the ${ }^{13} \mathrm{C}$ NMR CP/MAS spectra. The analysis was restricted to nonnegative spectra and non-negative concentrations. Two new matrices were obtained: the component concentrations of the components and the pure spectra classified by the component weights in this study, the component weights correspond to the spectral pattern of the first two components.

Statistical tests for comparing the means between soil types were performed for all the structure types in the original matrix and associated with the relative quantities of each carbon type. A statistical test tool was used for this purpose, and the KolmogorovSmirnov normality test was initially performed for each carbon type at a 5\%-confidence level. After confirming the normality of the data, the equivalence of variance (equality of variance) was verified using Bartlett's test, followed by comparing the means using the Student $\mathrm{t}$-test for equal variances.

\section{RESULTS AND DISCUSSION}

\section{Chemical and physical characteristics of superficial horizon from Inceptisol and Mollisol}

Significantly higher quantities of basic cations, $\mathrm{Ca}^{2+}, \mathrm{Mg}^{2+}, \mathrm{K}^{+}$ and $\mathrm{Na}^{+}$, and bases (as evidenced by the $\mathrm{S}$-value) were found in Mollisol than in Inceptisol $(p<0.001)$. The higher basic content of Mollisol resulted in a significantly higher V\% than in Inceptisol $(p<0.001)$; thus, Mollisol is classified as eutrophic (V\%> 50), and Inceptisol is classified as dystrophic $(\mathrm{V} \%<50) .{ }^{27}$ The Mollisol had a higher $\mathrm{P}$ content than Inceptisol $(p<0.001)$. However, Inceptisol had significantly higher $\mathrm{Al}^{3+}$ and $\mathrm{H}^{+}+\mathrm{Al}^{3+}$ contents $(p<0.001)$ than Mollisol. Both soils showed acidic $\mathrm{pH}$, but the Inceptisol $\mathrm{pHs}$ were significantly lower than the Mollisol pHs $(p<0.001)$, such that Inceptisol is classified as an acidic soil, whereas Mollisol is classified as moderately acidic.

Thus, the $\mathrm{Al}^{3+}$ saturation of the soil sorption complex was significantly higher in Inceptisol than in Mollisol, classifying Inceptisol as an alic soil $(>50 \%)(p<0.001)$. Both soils exhibited low $\mathrm{Na}^{+}$saturation, but the corresponding values were statistically higher in Mollisol than in Inceptisol. Mollisol had a statistically higher TOC content than Inceptisol $(p<0.001)$; however, the fulvic acid fractions of the two soils were not significantly different. Inceptisol had a statistically higher quantity of HA fraction than Mollisol $(p<0.001)$ and a correspondingly higher $\mathrm{C}-\mathrm{AH} / \mathrm{C}-\mathrm{AF}$ ratio $(p<0.001)$. The highest humin fraction was found in Mollisol and was significantly different from that of Inceptisol $(p<0.001)$ (Table 1S).

\section{Structural characterization of HA extracted from Inceptisol and Mollisol}

\section{Characterization of HA by ultraviolet-visible (UV-vis) spectroscopy}

The HA UV-vis spectra exhibited a typical HS pattern, that is, the absorbance increased from approximately $400 \mathrm{~nm}$ to $200 \mathrm{~nm}$. A shoulder at approximately $280 \mathrm{~nm}$, which is characteristic of aromatics and quinones, was observed in the HA spectra of Inceptisol and Mollisol. The most significant increase in the absorbance was observed above $300 \mathrm{~nm}$. This behavior is characteristic of compounds with unsaturated chemical systems. The color matrix graphic showed slight differences in the absorbance intensities at different wavelengths. The color scale of intensity shows that when compared to the Inceptisol HA spectra (orange: 7.74 and blue: 2.66), the UV-vis spectra for the Mollisol HA (orange: 8.57 and blue: 2.95) exhibited band peaks with higher absorbances in the orange and blue visible regions. The HA of Mollisol had intensities levels of absorbance superior in $10.72 \%$ when compare with $\mathrm{HA}$ of Mollisol. The $\mathrm{HA} \mathrm{E}_{4} / \mathrm{E}_{6}$ ratio for Mollisol was slightly lower than that for Inceptisol (Figure 1S).

\section{PCA analyses of UV-vis spectral data}

The PCA scores (98\% of total variance explained) were separated into $\mathrm{PC}-1$ positive values ( $90 \%$ of total variance explained) corresponding to HA samples mostly from Mollisol and PC-1 negative values (Inceptisol HA group). The average spectra, calculated by the 
descriptive statistics tools, were separated on both sides of PC-1, confirming the differences in the HA between the two soils (Figure 2A). The loadings that were obtained from the PCA and presented as UV-vis spectra show the weights for PC-1 (90\%) and PC-2 (8\%). This analysis shows that practically all region of greater spectrum contributes to the separation of HA from Mollisol (Figure 2B).
A)

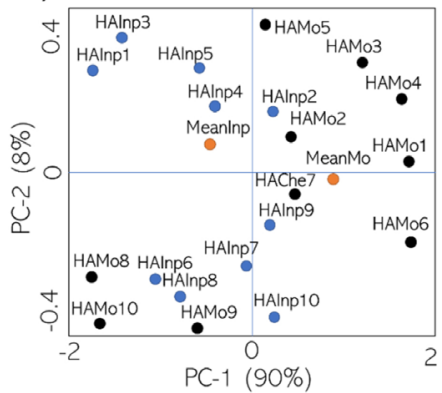

B)

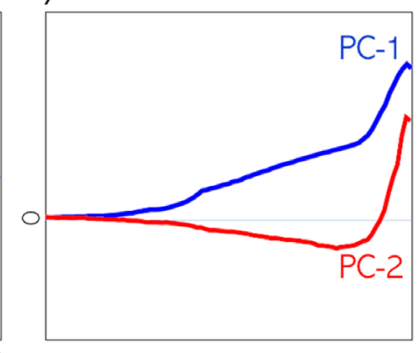

PC-1 (90\%), PC-2 (8\%)
Figure 2. Principal component analysis (PCA) based on UV-vis spectral data of HA extracted from Inceptisol (Inp) and Mollisol (Mo). A) Graphics of PCA scores and B) Graphics of PCA loadings in the spectral pattern form

\section{Characterization of HA by attenuated total reflection Fourier transform infrared spectroscopy (ATR - FTIR)}

The HA ATR-FTIR spectra for both soils were characteristic HS spectra (Figure $2 \mathrm{~S}$ ) ${ }^{36}$ In general, both spectra showed the presence of the chemical functional groups, $-\mathrm{OH},-\mathrm{CH}, \mathrm{COOH}$ and $\mathrm{C}=\mathrm{C}$, corresponding to aromatic and olefinic fragments, $-\mathrm{NH}$, etc. To elucidate the structural differences between the HA from the two soils, a detailed peak signaling analysis was performed on the absorption bands and is shown in Table $2 \mathrm{~S}$. The color matrix graphics for the Inceptisol HA exhibited high-intensity bands of 2.98; 3.84 and 3.41, indicating stretching of $-\mathrm{CH}\left(2964 \mathrm{~cm}^{-1}\right), \mathrm{COO}-\left(1624 \mathrm{~cm}^{-1}\right), \delta \mathrm{O}-\mathrm{H}$ and $\vee \mathrm{C}-\mathrm{O}\left(1247 \mathrm{~cm}^{-1}\right.$, corresponding to carboxylates $)$, respectively. The Mollisol HA spectra exhibited high-intensity bands of 4.02-4.59 between 1400 and $1600 \mathrm{~cm}^{-1}$, corresponding to aromatic groups ( $\vee \mathrm{C}=\mathrm{C}$ and $\nu$ in aromatic rings), and bands with an intensity of 3.45 at approximately $1070 \mathrm{~cm}^{-1}$, associated with polysaccharides (Figure 3A and 3B). The differences between the spectra are more evident when the average ATR-FTIR spectra are obtained. The shapes of the bands as well as their respective positions in the spectra reaffirm the results discussed above (Figure 3C and 3D).

\section{PCA analyses of ATR-FTIR spectral data}

The PCA scores ( $83 \%$ of total variance explained) were grouped on both sides of PC-1 (66\% of the explained total variance) (Figure 4). The Mollisol and Inceptisol HA were grouped with positive and negative values, respectively (Figure 4A). The spectral representation of the obtained loadings clearly confirmed the structural compositions of the two soils: aliphatic and hydroxyl functional groups were predominant in the Inceptisol HA, resulting in grouping with negative PC-1 values, whereas the predominance of aromatic and carbohydrate functional groups in the Mollisol HA resulted in grouping with positive PC-1 values (Figure 4B).

\section{Characterization of $\mathrm{HA}$ by carbon-13 cross-polarization magic-angle-spinning nuclear magnetic resonance spectroscopy $\left({ }^{13} \mathrm{C}\right.$ NMR CP/MAS)}

An analysis of all the verified spectra shows similar structures for the HA extracted from the two soils, albeit at different relative

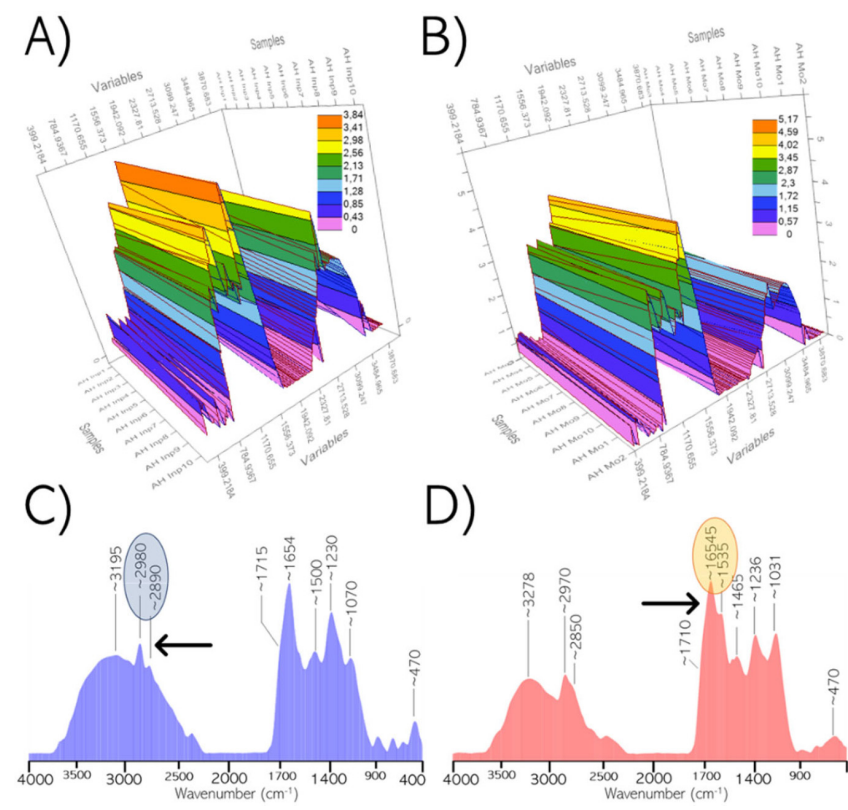

Figure 3. ATR-FTIR spectroscopy analysis for HA. A) Graphic matrix plot with intensity gradient and color scale of HA from Inceptisol (Inp) $(n=10)$ and B) Graphic matrix plot with intensity gradient and color scale of HA from Mollisol (Mo) $(n=10)$. C) ATR-FTIR average spectra of HA from Inceptisol (Inp) $(n=10)$ and D) ATR-FTIR average spectra of HA from Mollisol $(\mathrm{Mo})(n=10)$
A)

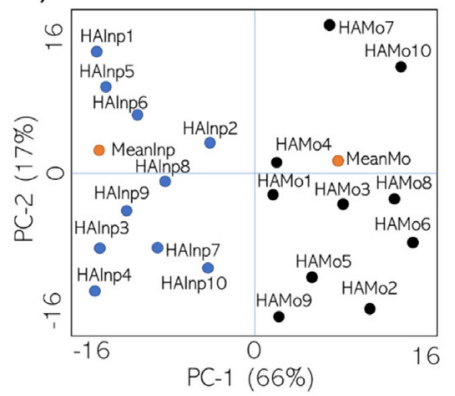

B)

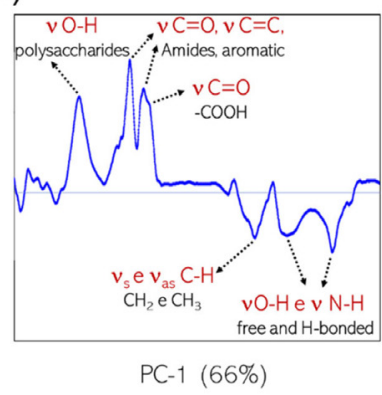

Figure. 4. Principal component analysis (PCA) based on ATR-FTIR pure spectral data of HA extracted from Inceptisol (Inp) and Mollisol (Mo). A) Graphics of PCA scores and B) Graphics of PCA loadings in the spectral pattern form

compositions. The spectra of both HA shown the presence of nonfunctionalized aliphatic carbons between 0 and $45 \mathrm{ppm}\left(* \mathrm{CH}_{3}-\mathrm{R}\right.$, $\mathrm{R} * \mathrm{CH}_{2}-\mathrm{R}$ ', R-CH-R'). These carbons occur in lipids, carbohydrates, amino acids and/or proteins and in the carbon chains of biopolymers, such as lignin, cutin, suberin and tannins. The spectra of both HA exhibit peaks between 45 and $60 \mathrm{ppm}$, corresponding to methoxy carbons $\left(\mathrm{RO}-* \mathrm{CH}_{3}\right)$ and polypeptides $\left(\mathrm{C}_{\mathrm{Alkyl}} \mathrm{O}, \mathrm{N}\right)$ of alpha carbons $\mathrm{C} \alpha\left(-\mathrm{CO}-{ }^{*} \mathrm{CHR}-\mathrm{NH}\right)$ from amino acids. The peaks between 60 and $90 \mathrm{ppm}\left(\mathrm{C}_{\mathrm{Alkyl}} \mathrm{O}\right)$ correspond to carbons $\left(-{ }^{*} \mathrm{C}-\mathrm{OH}\right)$ from cellulose/ hemicellulose and lignin fragments. The peaks between 90 and $110 \mathrm{ppm}\left(\mathrm{C}_{\mathrm{Alkyl}}-\right.$ di-O $)$ include anomeric carbons from carbohydrate fragments and $\mathrm{C} 2$ from syringyl and guayacil fragments. The peaks between 110 and $140 \mathrm{ppm}$ correspond to non-functionalized aromatic carbons $\left(\mathrm{C}_{\text {Aromatic }}-\mathrm{H}, \mathrm{R}\right)$ from syringil and guayacil of ligninic fragments $(\mathrm{C} 1)$. The peaks between 140 and $160 \mathrm{ppm}$ were assigned to functionalized aromatic carbons $\left(\mathrm{C}_{\text {Aromatic }} \mathrm{O}, \mathrm{N}\right)$ and phenolic fragments of lignin and suberin. The peaks between 160 and $185 \mathrm{ppm}$ correspond to carboxylic carbons $\left(-\mathrm{C}_{\mathrm{COOH}}\right)$ from fatty acid fragments. The peaks between 185 and $230 \mathrm{ppm}$ were assigned to carbonyl-type carbons $\left(\mathrm{C}_{\mathrm{C}=\mathrm{O}}\right)$ in ketones and aldehydes (Figure 3S). ${ }^{34,35,37}$ 
The scaled color matrix graphic confirms the ATR-FTIR results, that is, the Inceptisol HA contains predominantly fatty acid-like lipid fragments, whereas Mollisol HA contains predominantly aromatic structures and carbohydrates (Figure 5A and 5B). The ${ }^{13} \mathrm{C}$ NMR CP/ MAS average spectra obtained by descriptive chemometric analysis confirm the results shown above (Figure 5). The average spectra of HA extracted from Mollisol shows the high presence of aromatic carbons when compared to the HA from Inceptisol (Figure 5D). In contrast, the average spectra of HA extracted from Inceptisol shows the high relative amount of aliphatic carbons present in this structure (Figure 5C).


Figure 5. The ${ }^{13} \mathrm{C}-\mathrm{NMR}$ CP/MAS spectroscopy analysis for HA A) Graphic matrix plot with intensity gradient and color scale of HA from Inceptisol (Inp) $(n=10)$ and B) Graphic matrix plot with intensity gradient and color scale of HA from Mollisol (Mo) $(n=10)$. C) ${ }^{13} \mathrm{C}$-NMR CP/MAS average spectra of $H A$ from Inceptisol (Inp) $(n=10)$ and D) ${ }^{13} C-N M R C P / M A S$ average spectra of HA from Mollisol (Mo) $(n=10)$

\section{Descriptive analysis of ${ }^{13} \mathrm{C}$-NMR CP/MAS spectra}

A box-plot of the Inceptisol HA spectra exhibited a high structural variability in the $\mathrm{C}_{\text {Alkyl }}-\mathrm{H}, \mathrm{R}$ spectral region (Figure 6). The highest variability was observed between $40-45 \mathrm{ppm}$ in the HA of Inceptisol. The box-plot confirms the predominant functional groups in the Mollisol HA as $\mathrm{C}_{\mathrm{Alkyl}}-\mathrm{O}, \mathrm{N}$ and $\mathrm{C}_{\mathrm{Alky}} \mathrm{O}$, corresponding to peptides, carbohydrates, aromatic structures $\mathrm{C}_{\text {Aromatic }}-\mathrm{H}, \mathrm{R}$ and lignin derivatives (Figure 6B). The spectral regions between 46 and $50 \mathrm{ppm}$ and between 125 and $128 \mathrm{ppm}$ were magnified to show the high structural variability of these regions in comparison with other regions (Figure 6).

\section{PCA analysis of ${ }^{13} \mathrm{C}-\mathrm{NMR}$ CP/MAS spectra}

PCA was performed on the pure spectra ( $77 \%$ of total variance explained) to analyze the different types of carbons in the AHs of the two soils. The PCA scores showed two major HA groupings on both sides of the PC-1 ( $66 \%$ of the total variance explained). The Inceptisol HA and its medium spectrum were grouped at

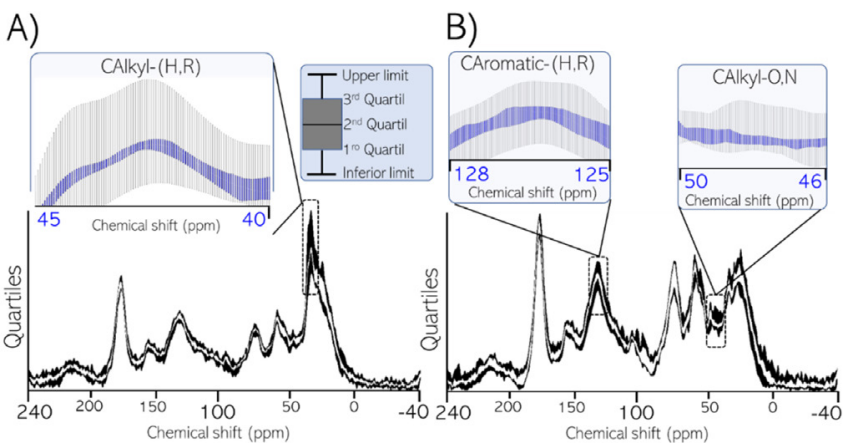

Figure 6. Descriptive statistics analysis performed from the data matrix of pure spectra representing the spectral variability for each variable in the matrix in quartile graphs (box-plot). A) Box-plot spectral graph for HA extracted from Inceptisol $(n=10)$. B) Box-plot spectral graph for HA extracted from Mollisol ( $n=10)$

positive PC-1 values, whereas the Mollisol HA were grouped with negative PC-1 values (Figure 7A). The spectral representation of the PC-1 loadings clearly confirm that non-functionalized aliphatic structures predominate in HA group from Inceptisol, whereas more functionalized structures contribute to higher structural variation in the Mollisol HA (Figure 7B).

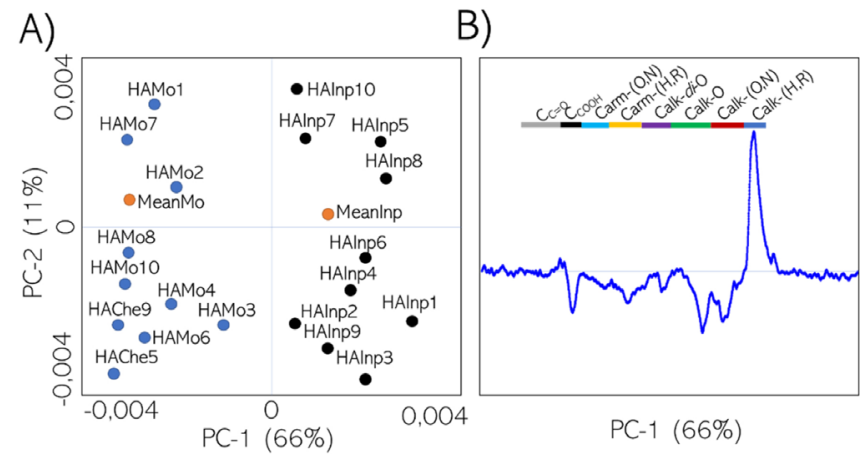

Figure 7. Principal component analysis (PCA) based on ${ }^{13} \mathrm{C}-\mathrm{NMR} C \mathrm{CP} / \mathrm{MAS}$ pure spectral data of HA extracted from Inceptisol (Inp) and Mollisol (Mo). A) Graphics of PCA scores and B) Graphics of PCA loadings in the spectral pattern form

\section{Comparative analysis of HA structural relative quantity using ${ }^{13}$ C NMR CP/MAS}

The Inceptisol HA exhibited a higher $\mathrm{C}_{\mathrm{Alkyl}}-\mathrm{H}, \mathrm{R}$ content $(32.3 \%)$ than the Mollisol HA (24.74\%), and the relative quantities were significantly different $(p<0.001)$. Similarly, the Inceptisol $\mathrm{HA}$ contained higher and significantly different quantities of $\mathrm{C}_{\mathrm{C}=\mathrm{O}}$ $(6.37 \%)(p<0.001)$ than the Mollisol HA (5.20\%). The Mollisol HA contained higher and significantly different quantities of $\mathrm{C}_{\mathrm{Alkyl}} \mathrm{O}, \mathrm{N}$ $(12.01 \%)(p<0.001)$ than the Inceptisol HA $(8.62 \%)$. The Mollisol $\mathrm{HA}$ contained higher and significantly different quantities of $\mathrm{C}_{\mathrm{Alkyl}} \mathrm{O}$ structures (13.24\%) than the Inceptisol HA (11.30\%). The Mollisol HA contained higher $(18.64 \%)$ and significantly different $(p<0.001)$ quantities of aromatic structures than the Inceptisol HA (16.43\%). The relative quantities of $\mathrm{C}_{\text {Alkyl }}-d i-\mathrm{O}, \mathrm{C}_{\text {Aromatic }}-\mathrm{H}, \mathrm{R}$ and $\mathrm{C}_{\mathrm{COOH}}$ structures were not significantly different in the Inceptisol and Mollisol HA (Figure 8A).

A quantitative property analysis showed that the Mollisol HA had higher $(26.17 \%)$ and significantly different $(23.41 \%)$ aromaticity than the Inceptisol HA. The hydrophobicity index was similarly calculated, showing that the Inceptisol HA is statistically $(p<0.001)$ more hydrophobic than the Mollisol HA (Figure 8B and 8C). 
A)

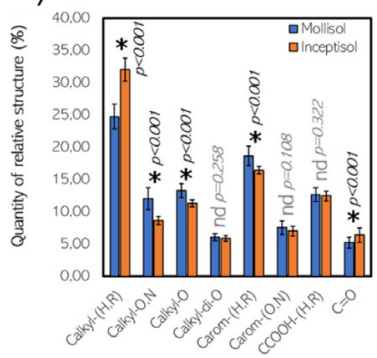

B)

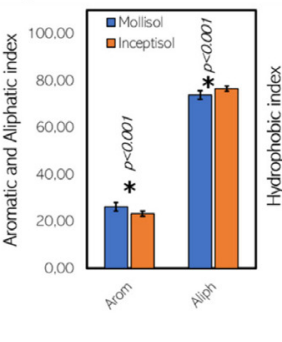

C)



Figure 8. Quantification and properties of HA extracted from Inceptisol $(n=10)$ and Mollisol $(n=10)$. A) Relative quantities of carbon types and test of means comparison (t-student). B) Aromatic and aliphatic properties calculated from the relative quantities obtained from the spectra. $C)$ Hydrophobicity index property $(\mathrm{HB} / \mathrm{HL})$ calculated from the relative quantities obtained from the spectra

\section{Multivariate curve resolution (MCR) of ${ }^{13} \mathrm{C}$ NMR CP/MAS spectra}

The MCR showed that the Inceptisol HA do not have distinct or easily identifiable hydrophobicity/hydrophilicity characteristics. The analysis showed that the polar and non-polar structures in the supramolecular organization contribute similarly to the hydrophobicity/hydrophilicity (Figure 9A). By contrast, in the MCR of the Mollisol HA, the hydrophobic $\left(\mathrm{C}_{\mathrm{Alkyl}}-\mathrm{H}, \mathrm{R}\right.$ and $\left.\mathrm{C}_{\text {Aromatic }}-\mathrm{H}, \mathrm{R}\right)$ and hydrophilic $\left(\mathrm{C}_{\mathrm{Alkyy}} \mathrm{O} ; \mathrm{C}_{\mathrm{Alky} \mid} \mathrm{O}, \mathrm{N} ; \mathrm{C}_{\mathrm{Alkyl}}-d i-\mathrm{O} ; \mathrm{C}_{\text {Aromatic }}-\mathrm{O}, \mathrm{N} ; \mathrm{C}_{\mathrm{COOH}}\right.$ and $\mathrm{C}_{\mathrm{C}=\mathrm{O}}$ ) patterns were easier to identify visually (Figure $9 \mathrm{~B}$ ). However, when MCR was performed for the HA from both soils, the hydrophobicity/hydrophilicity characteristics were difficult to identify. This result shows that in poorly evolved tropical soils, the humic suprastructure is not well formed and its development may be hindered by the soil mineralogical characteristics (Figure 9C).

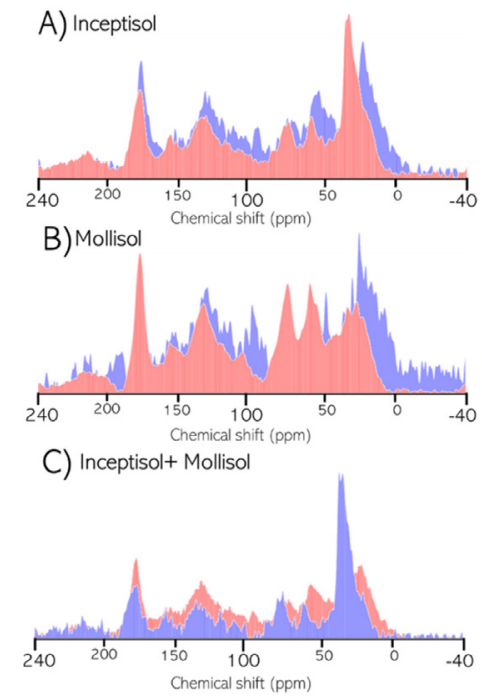

Figure 9. Multivariate curve resolution (MCR) applied to pure spectra where the weight components of the spectral matrices are shown for each type of soil and together $(n=20)$. Different colors should indicate different patterns of hydrophobicity and hydrophilicity when they exist. In MCR for Mollisol (where hydrophobicity and hydrophilicity were more differentiates, the spectral patterns represented by Blue color is assumed as hydrophobicity and red color as hydrophilicity)

\section{Chemical attributes of the superficial horizon in Mollisol and Inceptisol}

The attribute values obtained for Mollisol and Inceptisol match the characteristics used to classify these soils. ${ }^{27}$ The high TOC of Mollisol is coherent with the soil textural characteristics. The presence of a more heterogeneous mineral matrix in Mollisol, ${ }^{38}$ the $45.3 \%$ more of clay content and $49.1 \%$ more of silt when compared to Inceptisol (see material and methods), besides, the superior proportion of 2:1 clay in Mollisol provides a large number of sites and a high surface area for organomineral interactions and stabilization of organic carbon. ${ }^{38}$ This interaction capacity is limited in Inceptisol, wherein the mineralogy is predominantly coarse sand and primary minerals. These results explain the high levels of C-humin in Mollisol since this humic fraction constitutes the C-organic that is most strongly bound to the mineral fraction in soil. However, the same quantity of FA formed in both soils, showing similar initial processes for SOM incorporation. In both soils, the humified carbon content is higher in fractions with more advanced humification, such as $\mathrm{AH}$ and humin.

The studies carried out about classification of soil horizons in the same region of this study, reaffirm the characteristics of the mineral matrix reported in this research, especially for Inceptisols. ${ }^{27}$ Similar to that obtained in this study, the predominant mineral matrix in these soils, provides the chemical environment for carbon accumulation mainly in the humin chemical form and with higher quantity when compared to the FA fraction. ${ }^{39}$ Likewise, it was studied that the mineralogy of the region influences the presence of phosphorus remaining in the soil, a result that clearly shows the role of the mineral matrix of the soil in the formation of organo-mineral interactions and nutrients availability. ${ }^{40}$

\section{Characterization of humic acids and hypothetical mechanisms for carbon stabilization}

The $\mathrm{E}_{4} / \mathrm{E}_{6}$ ratios for a HS can indicate the amount of aromatic condensation in some studies and the others, has been show a correlation with, which has been related to the extent of SOM humification. ${ }^{41}$ Compared to the Inceptisol HA spectra, the Mollisol UV-Vis spectra showed higher aromaticity (see the number of structures in Figure 8), corresponding to HA with more quantity of condensed aromatic rings and as a consequence, an advanced OM humification process in these soils. The ATR-FTIR spectra confirmed the results from UV-vis spectroscopy and the $\mathrm{E}_{4} / \mathrm{E}_{6}$ ratio, that is, the higher aromatic presence in the Mollisol HA, and therefore possibly higher aromatic condensation, than in the Inceptisol HA; the ${ }^{13} \mathrm{C}$ NMR CP/MAS spectra showed that the HA in this study that were extracted from an Inceptisol and Mollisol are different from those found in soil with a more advanced degree of pedogenetic evolution. For example, in a previous study by García et al. ${ }^{17} \mathrm{HA}$ obtained from Histolsols (37 humic fractions (HA and humin) extracted from organic horizons in different soils) had higher quantities of aromatics, carbohydrates, and proteins that the HA investigated in the present study.

Tropical soils are well weathered naturally and the presence of mineral structures with limited ability to interact with SOM constitute barriers to carbon storage. However, in this study it was observed that preserved structures with a hydrophobic character, such as lipids, specifically fatty acids, cutin, and waxes, that are deposited in soil can evolve to form HA in Inceptisols and Mollisols. This hydrophobic interaction can be favored by the high sand content of Inceptisol, wherein the charge deficiency of the hydrophobic surface facilitates the formation of covalent and electrostatic bonds. The presence of organic compounds with long aliphatic chains also produces hydrophobic properties that facilitate interactions with the mineral fraction, which serves as the main humification mechanism in this soil. Mollisol has a clay-sandy texture, and the high number of clay particles can act as bridges between metals and polar compounds, such as carbohydrates, and aromatic compounds, enabling the formation of chemical bonds. 
Chemical characteristics of the compounds that reach the soil are decisive for the humification process of SOM and subsequent, for C. ${ }^{42}$ It is well accepted in the literature that during humification, the $\mathrm{C}_{\mathrm{Alkyl}}, \mathrm{C}_{\text {Aromatic }}-\mathrm{O}, \mathrm{N}$ and $\mathrm{COOH}$ structures slightly increase and that alkyl structures in the soil may participate in the humification through specific reactions, ${ }^{42,43}$ however, today we know that hydrophobic interactions play a fundamental role for organo-mineral interactions. ${ }^{44}$ In this line, it is possible to indicate that in these soils there is evidence of the humification process occurrence, especially for Inceptisol. These results are especially important because the humification leads to the stability of SOM, however, this process must be analize in specific form to each soil according to its characteristics. Similar HA characteristics to those observed this study were found by Gomes et al. ${ }^{45}$ for HA formed in different sandy soils with an organic carbon stock deficiency, that is, a low aromatic content and predominantly aliphatic and hydrophobic structures.

\section{Possible organomineral interactions in Inceptisol and Mollisol}

A textural analysis of Inceptisol indicates a total sand content of approximately $48 \%$, predominated by coarse sand (31\%), that is, large uncharged particles with a low specific surface area that are therefore, predominantly hydrophobic and dominate the organomineral interactions in this soil. Although hydrophobic interactions in soil are not well understood, these interactions are known to be sufficiently strong to stabilize organic compounds in soil. From a thermodynamic perspective, hydrophobic interactions are spontaneous in physicochemical terms $(\Delta \mathrm{G}<0)$. The stability of a hydrophobic interaction increases with the number of carbon atoms, temperature and shape of organic molecules involved. This last aspect is fundamental and explains why aliphatic molecules produce more stable interactions than aromatic molecules. ${ }^{44}$ One possible explanation of this behavior can be attributed to the higher surface area of aliphatic chains than aromatics.

The stronger interactions of aliphatic structures than aromatics can explain why the HA formed in Inceptisol was predominantly aliphatic. However, as aromatic compounds were present in the Inceptisol HA, it is possible that aromatics have hydrophobic interactions on available sites on the protonated surface of clay. The available hydrophilic polar groups can also serve as bridges that bind metals with other compounds, such as proteins, or act as sites for electrostatic interactions. The data obtained in this study suggest that in soils with these hydrophobic characteristics, that is, a sandy or similar texture, less complex HA formation occurs, resulting in predominantly aliphatic structures. These results are in line with studies carry out by Lin and Simpson, ${ }^{46}$ where was evidenced that fragment of suberin and cutin are preserved in soil thought physical protection. A schematic of this hypothetical mechanism is shown in Figure 10.

The organo-mineral mechanisms exemplified above also apply to Mollisol. However, the type 2:1 clay in Mollisol has permanent negative surface charges that provide a large number of interaction sites that act as bridges between proteins and metals. As discussed earlier, these interactions probably result in the higher protein and total glomalin content of Mollisol HA compared to Inceptisol HA (Figure 11).

\section{CONCLUSIONS}

Humified compounds in soils with different characteristics were studied. The texture of a soil controls the organomineral interactions and, therefore, the stabilization mechanisms in the soil. The HA formed in a soil with a high degree of pedogenesis (Mollisol)

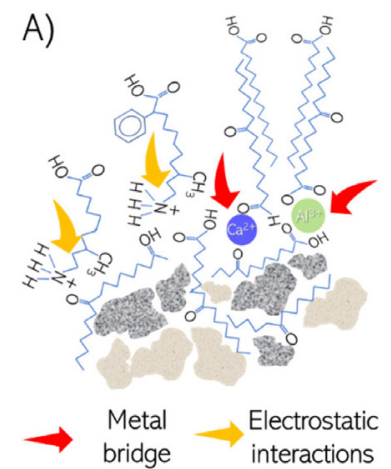

B)
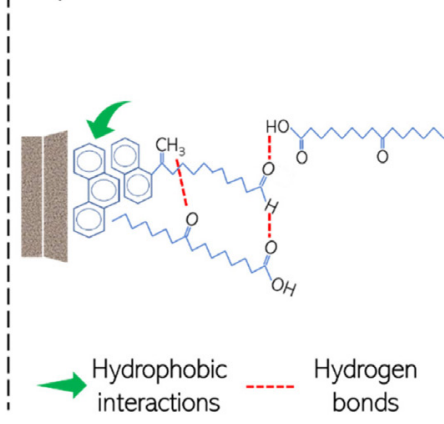

Figure 10. A) Stabilization through hydrophobic aliphatic interactions between waxes, cutins and aliphatic compost with the hydrophobic surface of the sand. In this model, the hydrophobic region is in interaction with the sand surface and the polar domain for the surface, providing other interactions. B) Hydrophobic interactions between 1: 1 clays and aromatic compounds. These interactions can occur in tropical soil with acidic $\mathrm{pH}$, since the surface of these clays are protonated, allowing hydrophobic interactions. These hypothetical interactions were taken and modified following the proposal by Kleber et al. (2007). ${ }^{47}$

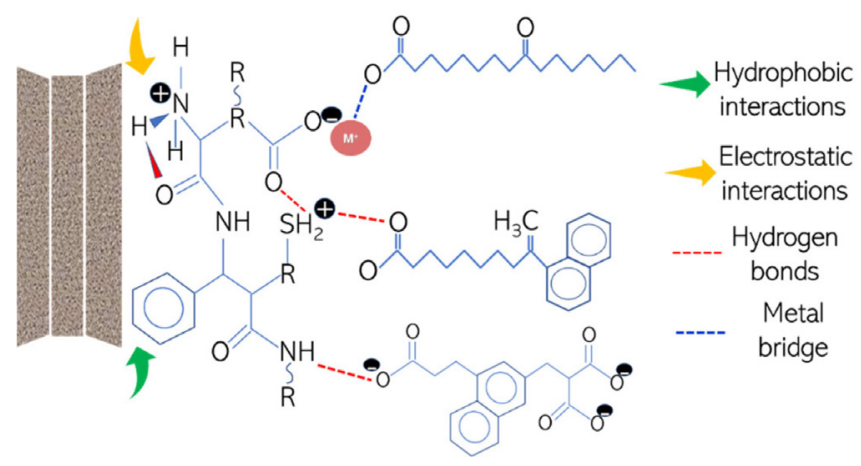

Figure 11. Hypothetical mechanisms for organo-mineral interactions with protein compounds for the stabilization of organic components in the Mollisol. These electrostatic interactions can take place between the 2: 1 permanently negatively charged surface of clays and the protonated amino groups in the proteins. These hypothetical interactions were taken and modified following the proposal by Kleber et al. (2007). ${ }^{47}$

has different structures and properties than the HA formed in an Inceptisol. The basic structures in HA formed in Inceptisol derive from unsubstituted aliphatic structures $\left(\mathrm{C}_{\text {Alkyl }}-\mathrm{H}, \mathrm{R}\right)$ and carbonyl carbons $(\mathrm{C}=\mathrm{O})$ and therefore have a high degree of aliphaticity and hydrophobicity. The HA formed in Mollisol are predominantly aromatic but have a high content of functionalized $\mathrm{C}_{\mathrm{Alky}} \mathrm{O}, \mathrm{N}$ and $\mathrm{C}_{\mathrm{Alkyl}} \mathrm{O}$ structures and therefore, a lower degree of hydrophobicity when compared to HA in Inceptisol. The structures and predominant presence of uncharged surface sand particles in Inceptisol result in the stabilization of organic carbon presumably mediated by hydrophobic interactions. The presence of clay (2:1 clay) of Mollisol provide different interaction sites for protein stabilization. The combination of spectroscopic characterization techniques with chemometric analyzes provides a study tool for explaining the characteristics and heterogeneity of structures in SOM.

\section{SUPPLEMENTARY MATERIAL}

Tables with information on the chemical attributes of the soils used as well as the assignment of the ATR-FTIR spectra with the identification of absorption bands and vibration modes of the different 
chemical groups (Table $1 \mathrm{~S}$ and Table 2S); also, the figures showing the UV-vis spectra of humic acids, $\mathrm{E}_{4} / \mathrm{E}_{6}$ ratio, as well as the ATRFTIR spectra and the ${ }^{13} \mathrm{C}-\mathrm{NMR}$ CP/MAS spectra (Figure 1S, Figure $2 \mathrm{~S}$ and Figure $3 \mathrm{~S}$ ), can be found at supplementary material and free of charge at http://quimicanova.sbq.org.br.

\section{ACKNOWLEDGMENTS}

SisFAPERJ: 2012028010 thanks the Fundação de Amparo à Pesquisa do Estado do Rio de Janeiro (FAPERJ) for supporting the research through Edital No. 04/2018- JCNE. Thanks to the Brazilian National Research Council (CNPq) for the research grant fellowship (No. 306867/2018-4, CNPq-No. 09/2018, Bolsa de pesquisa PQ-2). This study was financed in part by the Coordenação de Aperfeiçoamento do Pessoal de Nível Superior-Brasil (CAPES), Finance Code 001.

\section{REFERENCES}

1. Kögel-Knabner, I.; Zech, W.; Hatcher, P. G.; Soil. Sci. Soc. Am. 1991, 55,241 .

2. Stevenson, F. J.; Goh, K. M.; Geochim. Cosmochim. Acta 1971, 35, 471.

3. Kononova, M. M. In Soil organic matter, its nature, its role in soil formation and in soil fertility; Kononova, M. M., eds.; Pergamon Press, 1961, cap. 5.

4. Hatcher, P. G.; VanderHart, D. L.; Earl, W. L.; Org. Geochem. 1980, 2, 87.

5. Hayes, M. H.; MacCarthy, P.; Malcolm, R. L.; Swift, R. S.; Humic substances II. Search of Structure, $1^{\text {st }}$ ed., John Wiley and Sons: Chichester, 1989.

6. Piccolo, A.; Spaccini, R.; Drosos, M.; Vinci, G.; Cozzolino, V.; In The future of soil carbon; Garcia, C., Hernandez, T., eds.; Academic Press: Cambridge, 2018, pp. 87.

7. García, A. C.; van Tol de Castro, T. A.; Santos, L. A.; Tavares, O. C. H.; Castro, R. N.; Berbara, R. L. L.; García-Mina, J. M.; J. Environ. Qual. 2019, 48, 1622.

8. Sarker, T. C.; Incerti, G.; Spaccini, R.; Piccolo, A.; Mazzoleni, S.; Bonanomi, G.; Soil. Biol. Biochem. 2018, 117, 175.

9. Drosos, M.; Nebbioso, A.; Piccolo, A.; Appl. Soil. Ecol. 2018, 123, 513.

10. Sen, D. O. U.; Jun, S. H. A. N.; Xiangyun, S. O. N. G.; Rui, C. A. O.; Meng, W. U.; Chenglin, L. I.; Song, G. U. A. N.; Pedosphere 2020, 30 , 159.

11. Olk, D. C.; Bloom, P. R.; Perdue, E. M.; McKnight, D. M.; Chen, Y.; Farenhorst, A.; Harir, M.; J. Environ. Qual. 2019, 48, 217.

12. Brock, O.; Kooijman, A.; Nierop, K. G.; Muys, B.; Vancampenhout, K.; Jansen, B.; Org. Geochem. 2019, 134, 66.

13. Schmidt, M. W.; Torn, M. S.; Abiven, S.; Dittmar, T.; Guggenberger, G.; Janssens, I. A.; Nannipieri, P.; Nature 2011, 478, 49.

14. Lehmann, J.; Kleber, M.; Nature 2015, 528, 60.

15. Kleber, M.; Lehmann, J.; J. Environ. Qual. 2019, 48, 207.

16. Sherrod, L. A.; Vigil, M. F.; Stewart, C. E.; J. Environ. Qual. 2019, 48, 1587.

17. García, A. C.; De Souza, L. G. A.; Pereira, M. G.; Castro, R. N.; GarcíaMina, J. M.; Zonta, E.; Berbara, R. L. L.; Sci. Rep. 2016, 6, 1.

18. Soucemarianadin, L. N.; Erhagen, B.; Nilsson, M. B.; Öquist, M. G.; Immerzeel, P.; Schleucher, J.; Org. Geochem. 2017, 113, 184.
19. Hatcher, P. G.; Waggoner, D. C.; Chen, H.; J. Environ. Qual. 2019, 48, 1571.

20. Vialykh, E. A.; Salahub, D. R.; Achari, G.; Cook, R. L.; Langford, C. H.; Environ. Chem. 2019, 16, 505.

21. Conte, P.; Berns, A. E.; Anal. Sci. 2008, 24, 1183.

22. Chen, C.; Leinweber, P.; Eckhardt, K. U.; Sparks, D. L.; Soil Syst. 2018, 2,16 .

23. Ramos, F. T.; Dores, E. F. D. C.; Weber, O. L. D. S.; Beber, D. C.; Campelo Jr, J. H.; Maia, J. C. D. S.; J Sci Food Agr. 2018, 98, 3595.

24. Assunção, S. A.; Pereira, M. G.; Rosset, J. S.; Berbara, R. L. L.; García, A. C.; Sci. Total Environ. 2019, 658, 901.

25. Santos, A. D. C.; Pereira, M. G.; Anjos, L. H. C. D.; Bernini, T. D. A.; Cooper, M.; Nummer, A. R.; Francelino, M. R.; Rev. Bras. Cienc. Solo. 2013, 34, 1297.

26. Soil Survey Staff; Keys to Soil Taxonomy, $12^{\text {th }}$ ed., USDA-Natural Resources Conservation Service, Washington, DC, 2014.

27. Santos, H. G.; Jacomine, P. K. T.; Dos Anjos, L. H. C.; De Oliveira, V. A.; Lumbreras, J. F.; Coelho, M. R.; Cunha, T. J. F.; Brazilian Soil Classification System, Embrapa: Brasília, DF, 2018.

28. Yeomans, J. C.; Bremner, J. M.; Commun. Soil. Sci. Plant Anal. 1988, $19,1467$.

29. Benites, V. M.; Madari, B.; Machado, P. L. O. A., Comunicado Técnico 16, EMBRAPA Solos, Rio de Janeiro, Rio de Janeiro, 2003, 7p.

30. Swift, R. S., In Methods of soil analysis: chemical methods; Sparks, D. L., ed.; SSSA: Madison, 1996.

31. Song, G.; Novotny, E. H. Simpson, A. J.; Clapp, C. E.; Hayes, M. H. B.; Eur. J. Soil Sci. 2008, 59, 505.

32. Chen, Y.; Senesi, N.; Schnitzer, M.; Soil Sci. Soc. Am. J. 1977, 41, 352.

33. Kögel-Knabner, I.; Geoderma 1997, 80, 243.

34. Keeler, C.; Kelly, E. F.; Maciel, G. E.; Geoderma 2006, 130, 124.

35. Karpukhina, E.; Mikheev, I.; Perminova, I.; Volkov, D.; Proskurnin, M.; J. Soil. Sediment. 2019, 19, 2729.

36. Mao, J.; Tremblay, L.; Gagné, J. P.; Geochim. Cosmochim. Acta 2011, $75,7864$.

37. Mendes, E. C. Dissertação de Mestrado em Agronomia, Universidade Federal Rural do Rio de Janeiro, 2015.

38. Fontana, A.; Pereira, M. G.; dos Anjos, L. H. C.; dos Santos, A. C.; Bernini, T. A.; Rev. Cienc. Agron. 2014, 45, 221.

39. Fontana, A.; Pereira, M. G.; dos Santos, A. C.; Bernini, T. A.; dos Anjos, L. H. C.; Fernández, C. F. D.; Peinado, F. J. M.; Ciências Agrárias 2013, 34, 2089.

40. Saab, S. D. C.; Martin-Neto, L.; Quim. Nova 2007, 30, 260.

41. Zech, W.; Senesi, N.; Guggenberger, G.; Kaiser, K.; Lehmann, J.; Miano, T. M.; Schroth, G.; Geoderma 1997, 79, 117.

42. Kögel-Knabner, I.; de Leeuw, J. W.; Hatcher, P. G.; Sci. Total. Environ. 1992, 117, 175

43. Atkins, P.; de Paula, J.; Physical Chemistry for the Life Sciences, Oxford University Press, Oxford, 2006.

44. Gomes, M, E. T.; Berbara, R. L. L.; Pereira, M. G.; Urquiaga, S. S.; Tavares, O. C. H.; Assunção, S. A.; García, A. C.; Land Degradation \& Development 2018, 29, 68.

45. Lin, L. H.; Simpson, M. J.; Org. Geochem. 2016, 97, 111.

46. Kleber, M., Sollins, P.; Sutton, R.; Biogeochemistry 2007, 85, 9. 